\title{
UMA PEDAGOGIA CONTRA O OUTRO? COMPETITIVIDADE E EMULAÇÃO*
}

\author{
Licínio Carlos Viana da Silva Lima ${ }^{1}$
}

\begin{abstract}
RESUMO: Este artigo analisou algumas das mais importantes características das políticas educativas contemporâneas, especialmente aquelas que têm sido introduzidas pelas reformas gerencialistas da educação pública. Retomando vários trabalhos que publicou ao longo dos últimos anos sobre esse tema, o autor destacou o processo de impregnação empresarial das escolas, a privatizaçáo lato sensu como princípio reformador, a hegemonia da educação e formação vocacional, as práticas meritocráticas promotoras de desigualdades e a crise da democracia nas escolas. Concluiu que a competitividade exacerbada pela pedagogia empreendedorista e pelas correspondentes práticas de emulação nas escolas pode vir a resultar numa pedagogia contra o outro e numa educação alienante e desumanizada.
\end{abstract}

Palavras-chave: Política educacional. Impregnação empresarial das escolas. Pedagogia empreendedorista. Competitividade e desumanização da educação.

\section{A PEDAGOGY AGAINST THE OTHER? COMPETITIVENESS AND EMULATION}

ABSTRACT: This article analyzes some of the most important features of contemporary educational policies, especially those that have been introduced by the managerialist reforms of state education. Taking up several works published by the author over the last few years on this theme, he highlights the process of business impregnation of schools, the lato sensu privatization as a reforming principle, the hegemony of education and vocational training, meritocratic practices that promote social inequalities, the crisis of democracy in schools. He concludes that competitiveness exacerbated by entrepreneurial pedagogy and the corresponding practices of emulation in schools may result in a pedagogy against the other and in an alienating and dehumanized education.

Keywords: Educational politics. Business impregnation of schools. Entrepreneurial pedagogy. Competitiveness and dehumanization of education.

\footnotetext{
*Este trabalho é financiado pelo Centro de Investigação em Educação (CIEd), projetos UID/CED/1661/2013 e UID/CED/1661/2016, Instituto de Educação, Universidade do Minho, por meio de fundos nacionais da Fundação para a Ciência e a Tecnologia (FCT)/Ministério da Educação e Ciência de Portugal (MCTES-PT).

${ }^{1}$ Universidade do Minho, Instituto de Educação, Departamento de Ciências Sociais da Educação Braga, Portugal.

E-mail: llima@ie.uminho.pt
}

DOI: 10.1590/ES0101-73302019218952 


\section{UNA PEDAGOGÍA CONTRA EL OTRO? COMPETITIVIDAD Y EMULACIÓN}

RESUMEN: Este artículo analiza algunas de las características más importantes de las políticas educativas contemporáneas, especialmente aquellas que han sido introducidas por las reformas gerencialistas de la educación pública. El autor destaca el proceso de impregnación empresarial de las escuelas, la privatización lato sensu como principio reformador, la hegemonía de la educación y formación vocacional, las prácticas meritocráticas promotoras de desigualdades, la crisis de la democracia en las escuelas. Concluye que la competitividad exacerbada por la pedagogía emprendedora y las correspondientes prácticas de emulación en las escuelas pueden resultar en una pedagogía contra el otro y en una educación alienante y deshumanizada.

Palabras clave: Política educativa. Impregnación empresarial de las escuelas. Pedagogía empresarial. Competitividad y deshumanización de la educación.

\section{Introdução: impregnação empresarial das escolas}

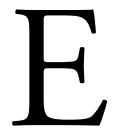

ntende-se por impregnaçáo empresarial das escolas o processo de instilação de várias dimensóes institucionais e organizacionais da empresa no novo capitalismo. Eixo central da estratégia de reformar a governaçáo da educação escolar pública sob os princípios do Estado gestionário (CLARKE; NEWMAN, 1997), do espírito empreendedor e do mundo dos negócios, a saturaçáo de elementos empresariais transcende a mera importaçáo ou exportação de modelos, de métodos e de técnicas, que, não sendo indiferentes, resultam de um complexo e decisivo processo de conversão e aculturação de atores e instituições a um arquétipo considerado superior em termos de legitimidade e de racionalidade (LIMA, 2018).

Sem a impregnação empresarial da educação, nas suas diferentes áreas e dimensōes, sem a capacidade de embeber as organizaçóes escolares dessa espécie de caldo normativo e cultural, à margem do reforço da legitimidade e do prestígio social que resulta daquela impregnação, as próprias dinâmicas de privatização lato sensu ficariam consideravelmente diminuídas, incapazes de atrair responsáveis políticos de quase todos os quadrantes ideológicos e também de despertar adesões e processos de recontextualização pedagógica das agendas gerencialistas. A organização de tipo mecanicista e as novas hierarquias, o eficientismo e o produtivismo, as parcerias e os contratos, o vocacionalismo e o empreendedorismo pedagógico, os novos processos de seleção, avaliação e atribuição de prêmios, o elogio da meritocracia e da competitividade como princípios educativos, entre outros elementos, conhecem aplicações muito diferenciadas, mas generalizadas, sob os lemas da racionalização, modernização e qualidade da educação. 
Propóe-se, aqui, a análise de apenas alguns desses elementos, com base em trabalhos realizados nos últimos anos pelo autor desse artigo e aqui retomados, procurando uma síntese possível que permita avançar no estudo e interrogar as políticas públicas tendo em consideração os riscos de desumanização da educação. Especial atenção é conferida ao lideracionismo e à concentraçáo de poderes num contexto de crise da gestão democrática das escolas, à competitividade exacerbada entre professores, entre alunos e entre escolas que, por vezes, se assemelha a um stakhanovismo educacional alienante e opressivo, podendo resultar numa educação desumanizadora e numa pedagogia contra o/a outro/a.

Trata-se, também, do resultado de um processo político e cultural de expansão e legitimação da empresa, do mercado e do mundo dos negócios a todas as áreas da atividade humana, incluindo a educação. Esta deixou de ser considerada uma realidade extraeconômica; pelo contrário, é hoje entendida como um instrumento de qualificação de mão de obra, um fator adiantado de competitividade, uma estratégia de crescimento econômico, de qualificação do capital humano e de gestão de recursos humanos.

A promoção de certo tipo de aprendizagens efetivas e de mentalidades empreendedoras, de qualificaçóes, competências e resultados de aprendizagem individualizados, integrando portfólios individuais competitivos, fez com que o conceito de educação fosse esbatido em muitos discursos políticos, substituído pelo elogio das aprendizagens individuais com elevado valor econômico. A ideologia empreendedorista vem reforçando as pedagogias empreendedoras sob uma missão clara, uma visão estratégica, uma liderança efetiva, um projeto e uma equipe, uma avaliação rigorosa dos resultados e sob a prestação de contas aos stakeholders. A "preparação para um futuro remoto", como lhe chamou John Dewey (2007, p. 82), em 1916, no seu livro Democracia e educação, agora de acordo com as exigências de empregabilidade, consolida certa ideia de empresa enquanto referencial institucional a que escolas e universidades não poderiam escapar, sem ser correndo os riscos de ficarem para trás, irracionalmente mergulhadas num universo burocrático que é apresentado como imanente ao setor público e à gestão pública. Nesse contexto, o mundo empresarial - agora apresentado como não burocrático ou como pós-burocrático pelo novo gerencialismo, ignorando a sociologia weberiana e mais de meio século de pesquisas teóricas e empíricas sobre a burocracia industrial e empresarial (ver, somente a título de exemplo, GOULDNER, 1954 e também CROZIER, 1964) — surge como força redentora e regeneradora, como a última esperança para reformar o Estado e as instituiçóes públicas.

\section{Reformas gerencialistas da educação}

Se o velho gerencialismo baseado em Frederick Taylor (1982) e Henri Fayol (1984), bem como na proposta de um "código universal" da boa gestão 
privada e pública, como foi chamado por Henry Ford (1995, p. 109), influenciou bastante a organização e a gestão das escolas ao longo do século XX, agora o novo gerencialismo insiste na mesma ideia de uma teoria geral da gestáo, que historicamente foi sempre específica (isto é, de extração empresarial e, particularmente, industrial), mas que alcançou já o estatuto de princípio reformador do próprio Estado e da gestão pública, muito para além do seu tradicional protagonismo no interior das teorias organizacionais, desde a chamada administração científica do início do século XX. A modernização, a racionalização e a qualidade da educação pública só seriam atingíveis por meio de novas teorias e práticas, políticas e organizacionais, atravessando todos os níveis, do Estado à sala de aula. A solução residiria na nova gestão e em novos gestores para reformar a educação e modernizar as escolas, à imagem das empresas privadas e do seu quadro de racionalidade econômica.

Apesar das diferenças entre si, as ideologias da gestão dos últimos 30 anos, incluindo a "reinvenção do governo", a "nova gestão pública", a "nova governança" (ver, entre outros, OSBORNE; GAEBLER, 1992; GORE, 1996; SALAMON, 2000; 2002), que por facilidade, embora correndo riscos de sincretismo e de falta de estudo das respectivas fontes primárias, se tem chamado criticamente gerencialismo, partilham vários elementos. Por essa razão têm sido criticamente designadas por perspectivas gerencialistas, solução compreensível, mas que não deixa de envolver riscos de sincretismo e, por vezes, de falta de estudo das respectivas fontes primárias. Em qualquer caso, estamos perante um cânone gerencialista, de que tenho destacado os seguintes elementos (LIMA, 2012b): a cultura e o ethos de tipo empresarial; a defesa da privatização, seja em sentido pleno, seja como modo de gestáo a ser introduzir nas organizaçóes públicas; o elogio da liderança individual e da respectiva visão e projeto, como expressão do direito de gerir, da livre iniciativa e do empreendedorismo na administração pública; a eficácia e a eficiência definidas segundo a racionalidade econômica; a livre escolha, em ambiente de mercado ou quase mercado competitivo, num quadro que coloca o cliente e o consumidor no centro das opçóes consideradas racionais; a clareza da missão da organização e a definição objetiva e passível de mensuração dos seus objetivos, escrutináveis por intermédio de rigorosos processos de avaliação.

As reformas gerencialistas da educação pública, embora com impactos variados e apropriações diversas, têm, de acordo com a investigação disponível (ver, a título de exemplo, SMYTH, 1993; 2011; VERGER; NORMAND, 2015; RANSON, 2016), destacado um vasto conjunto de dimensões, entre as quais: a centralização da formulação das políticas educativas e dos processos de decisão sobre o currículo e a avaliação, apesar de invocar a descentralização, a devolução e a autonomia da escola; a descentralização e, sobretudo, a desconcentração de certas competências, embora principalmente de caráter técnico e operacional e, por vezes, financeiro, alargando as fontes de financiamento a entidades privadas 
e responsabilizando de forma crescente as famílias dos alunos; a menor relevância atribuída a processos de controle democrático e de participaçáo nos processos de tomada das decisões, bem como a crescente desconfiança relativa a órgãos colegiados, normalmente vistos como fontes de desresponsabilização, de composição considerada numerosa e paralisante, de funcionamento pesado e lento; o reforço do poder dos gestores, assessores e outras tecnoestruturas (GALBRAITH, 1974), em prejuízo da influência dos profissionais, educadores e professores, bem como da comunidade e da diversidade das suas organizaçóes e dos seus interesses, em geral substituídos pela intervenção de representantes restritos dos interessados, pelo controle dos clientes, pelas parcerias com o poder econômico e empresarial; a governação e decisões políticas baseadas em evidências, instituindo formas de regulação de tipo mercantil; o reforço das estruturas de gestão de tipo vertical e concentração de poderes no líder formal.

Apresentada e legitimada como uma alternativa de tipo pós-burocrático - a grande promessa do novo gerencialismo —, revela-se, com frequência, como mais gestáo para menos democracia, sendo responsável por um aumento exponencial de certas dimensões da burocracia racional estudada e criticada por Max Weber (1984) e a que tenho chamado hiperburocracia ou burocracia eletrônica (LIMA, 2012a), já que se caracteriza por uma radicalização das dimensóes de racionalização e formalização da educação escolar, ampliada pelo recurso intensivo e extensivo às tecnologias de informação e comunicação e, ainda, da sua capacidade de controle (re)centralizado (ver também PEREIRA, 2009 e MEIRA, 2017).

\section{Privatização lato sensu}

O conceito de privatização lato sensu, em que tenho trabalhado (LIMA, 2018), pretende realçar as dimensóes institucionais, axiológicas e culturais enquanto elementos de legitimação na ordem político-educativa. Para além, portanto, da "importação de ideias, técnicas e práticas do setor privado para tornar o setor público mais como as empresas" (BALL; YOUDELL, 2008, p. 9). Não recusa, contudo, tal processo de importação, nem práticas miméticas ou isomórficas, como no caso daquilo que aqueles autores designaram por "privatização endógena". Mas a privatização lato sensu talvez tenha as vantagens conceituais de escapar à difícil demarcação de fronteiras entre "privatização endógena" e "privatização exógena”, para além de não se limitar à inclusão de processos de importação do setor privado para o setor público, incluindo processos de induçáo da privatização, quer com origem privada, quer com origem pública, e, ainda, de incluir não apenas processos de "privatizaçáo oculta", encoberta ou dissimulada. Sendo certo, como observaram Ball e Youdell (2008) no seu importante relatório, que existem formas de privatização que designaram por "endógena", dificilmente reconhecíveis enquanto tal pelos atores sociais implicados, até por não serem nomeadas aberta- 
mente, noutros casos, contudo, não é pelo fato de não serem claramente nomeadas enquanto formas de privatização que permanecem necessariamente ocultas. Seja porque são introduzidas por setores institucionais bem conhecidos, induzidas por meio de programas de financiamento, de ajustamento orçamental ou de ajuda internacional cuja origem é clara para os envolvidos, seja também porque resultam do estabelecimento de formas de cooperação com empresas privadas, fundaçóes e outras organizaçóes não governamentais, em certos casos intencionalmente procuradas pelos beneficiários em contextos de advocacia das virtudes do setor privado e do universo empresarial.

Há ainda que reconhecer, desde logo, no plano teórico, que os professores e outros atores educativos periféricos nem sempre serão vítimas, ou apenas alvos incautos e mais ou menos desprotegidos, de práticas de "endoprivatização", com caráter de comercialização ou não (SAURA; MUÑOZ, 2016, p. 46). Pelo contrário, há situaçóes em que aqueles se revelam atores estratégicos em busca de diferenciação institucional e de vantagens competitivas, mediante a introdução, intencional e refletida, de processos, regras e modos de gestão importados diretamente do setor privado ou induzidos de forma mediada e indireta por governos e outras entidades públicas; não apenas em termos procedimentais mais ou menos circunscritos, procurando obter determinados recursos e resultados, mas também em termos de adesão substantiva a quadros axiológicos, a agendas ideológicas e a doutrinas de gestão. Por exemplo, não apenas aderindo passivamente e de maneira subordinada, mas também promovendo ativamente a adesão a processos diversos que, em certos casos, não lhes são necessariamente externos, podendo contemplar a sua participação neles em termos de concepção e de operacionalizaçáo, como: a avaliação externa estandardizada, a avaliaçáo institucional, a participação e produção de informação requerida para a produção de rankings, a criação de sistemas de incentivos, as práticas de seleção de alunos, as formas de reforço da autonomia de gestão por parte de lideranças unipessoais, os processos de nomeação em prejuízo de processos de eleição de detentores de cargos de gestão pedagógica, as mudanças de estatutos no plano jurídico e/ou organizacional, a criaçáo de plataformas eletrônicas de gestão escolar e de outros instrumentos de controle etc.

A privatização lato sensu representa um vasto, diversificado e, por vezes, heterogêneo repertório de processos relativos à política, à gestão, ao currículo, à avaliação, à liderança etc., que, não obstante, pode aumentar as desigualdades sociais entre os alunos e a precariedade do estatuto e das condiçóes de trabalho dos professores. Esse repertório emerge dotado de uma aura de superioridade racional e como fonte de legitimação de políticas educativas e de práticas escolares, elevando o seu status social, confirmando culturalmente uma abertura à inovação e ao empreendedorismo, celebrando a competitividade diferenciadora, abrindo-se ao reconhecimento do mérito, promovendo as competências que são hiperbolicamente consideradas a chave para um futuro incerto. 


\section{Vocacionalismo}

Toma-se como referência, a título de exemplo, a Uniáo Europeia, para quem a educação, agora mais raramente, e sobretudo a aprendizagem são consideradas instrumentos, ferramentas indispensáveis à constituição de uma "força de trabalho habilitada, formada e adaptável” (UNIĀO EUROPEIA, 2001, p. 6), um investimento reprodutivo em termos de empregabilidade, produtividade e mobilidade, desta feita configurando aquilo que é anunciado como uma "nova abordagem" à educaçáo e formação ao longo da vida. Isso surge, reiteradamente, justificado por um clima econômico incerto e turbulento, o qual conduz a que uma renovada ênfase na importância da aprendizagem permanente seja colocada, uma vez que a obtenção de vantagens comparativas "é crescentemente dependente do investimento em capital humano", transformando o conhecimento e as competências "num poderoso motor para o crescimento econômico" (UNIÃO EUROPEIA, 2001, p. 6).

Perante os desafios declarados da competitividade e performance econômicas, a aprendizagem permanente deve passar a ser dirigida em resposta às necessidades e aos problemas da Europa, tanto mais que, nesse sentido, "nunca é tarde para aprender" (UNIĀO EUROPEIA, 2006a), ou seja, para promover a adaptabilidade e um "espírito empreendedor" que garanta desenvolvimento econômico, sustentabilidade, melhores empregos e mais coesão social (UNIÃO EUROPEIA, 2006b, p. 21). Aqui se procede, conceitualmente, à disjunção entre "formação vocacional", como aquela que é dirigida para o trabalho, e "educação de adultos", como compreendendo "todas as formas de aprendizagem dos adultos de tipo não vocacional, sejam de natureza formal, não-formal ou informal" (UNIÁO EUROPEIA, 2006b, artigo 2. ${ }^{\circ}$ ). Mas mesmo o conceito de educaçáo de adultos, como concluiu Ettore Gelpi (2009, p. 161), passou a adquirir conotação redutora, reprodutiva e tecnocrática: "Para nada antecipadora, a educação de adultos é amiúde herdeira de uma organização, de uma linguagem, de uma prática que se destacaram no exército e na fábrica”.

As competências-chave de que cada indivíduo deverá apropriar-se fornecem valor acrescentado para o mercado de trabalho, flexibilidade e adaptabilidade, resultando de uma combinaçáo entre conhecimento, habilidades e atitudes adequadas e funcionalmente adaptadas a cada contexto: mais flexibilidade, mais adaptação, inovação, produtividade, competitividade e qualidade do trabalho (UNIÂO EUROPEIA, 2006c). É sob essa perspectiva vocacionalista que prosseguirão as estratégias europeias no domínio da educação e formação até 2020, segundo as conclusóes do Conselho Europeu de 12 de maio de 2009 (UNIÂO EUROPEIA, 2009, p. 2): "Investir eficazmente em capital humano através dos sistemas de educação e formação constitui componente essencial da estratégia adotada pela Europa". Novamente, e de forma mais intensa, surgem os desígnios da empregabilidade e da adaptabilidade das pessoas, a aquisição de competências- 
-chave para a excelência e a atratividade, a necessidade de incentivar a criatividade e a inovação, incluindo o "espírito empreendedor", tendo em vista o desenvolvimento das empresas e a competitividade da Europa a nível mundial.

\section{Educação contábil e meritocracia}

Há mais de duas décadas que escrevi sobre o que designei por educação contábil (LIMA, 1996; 1997): a educação que é orientada para a performatividade competitiva, segundo o já antes referido cânone gerencialista, com seus objetivos precisos e seus resultados rigorosamente quantificados, dessa forma tornando-se passível de medição, de comparação e de hierarquização. Com efeito, a educação contábil define a educação que conta em função do caráter contável, mensurável e comparável dos "resultados" escolares produzidos, tendendo a conceitualizar o aluno como uma "matéria-prima" moldável por meio de processos de "produçáo" escolar. Nesse quadro de referência, a chamada "garantia da qualidade" ocorre perante um sistema de critérios de aplicação universal do qual resultará a produção de juízos de qualidade diferenciados, por eles distinguindo, comparando e hierarquizando, uma vez que o pressuposto é o da qualidade como propriedade rara, ou escassa, assimetricamente distribuída, por vezes mediante quotas previamente fixadas, no interior de dada população.

Tal como no caso da definição de problemas a enfrentar e de soluçóes a adotar nos modernos sistemas escolares, hoje definidos por influentes organizaçôes internacionais como se fossem universais ou, pelo menos, como se não fossem contingentes nem culturalmente situados, também a avaliação da qualidade educacional tende a ser apresentada como um imperativo racional e de modernização. Por essa razão se considera uma irracionalidade de gestão, uma utopia pedagógica ou um subjetivismo irresponsável todo um vasto conjunto de modalidades e práticas de avaliação de natureza formativa, democrática, dialógica, negociada ou participada. Assim se compreende o protagonismo da mensuraçáo, da descrição objetiva da realidade e de certo fetichismo em torno dos "dados" que melhor permitem a competitividade e a emulação, mesmo quando possam ser acusados de realismo ingênuo ou de "cilada do objetivismo" (HADJI, 1994, p. 97). Os processos dominantes nessa avaliação evidenciam uma espécie de "quantofrenia", de acordo com o conceito usado pelo sociólogo Pitirim Sorokin (1965) em meados do século XX, então a propósito das ciências psicossociais, mas que podemos estender à educação e à pedagogia oficial. Sorokin (1965, p. 51) chamou a atenção para a "testomania", que, segundo ele, conduziu à seguinte situação: "Quase todo o indivíduo é testado do berço à cova, antes e depois de importantes acontecimentos da sua vida", mediante a açáo dos respectivos "testocratas". Segundo ele, a matemática foi instrumentalizada a serviço daquilo a que chamou o culto da numerologia. Uma espécie de nova doença terá emergido: a "quantofrenia". 
Um movimento que continua atual e que Martin Lawn (2013, p. 108) caracterizou como de "ascenção da especialidade da medição", a que se pode acrescentar a nova condição dos professores como educometristas.

É por isso visível, no contexto de uma avaliação "quantofrênica", o protagonismo crescente dos estudos em torno dos exames, dos testes e do cálculo, até porque são politicamente representados como indispensáveis à produção de métodos e instrumentos mais objetivos e fidedignos na captaçáo da realidade, mais exigentes em termos pedagógicos e mais rigorosos na produção de resultados, assim configurando uma avaliação hiperburocrática (LIMA, 2016).

A educação contábil é indispensável à constituição de regimes meritocráticos. A produção de uma imagem cultural e simbólica associada a uma escola empreendedora, competitiva, com liderança carismática, em busca da excelência de resultados, incentivando a melhoria constante e a garantia da qualidade, projetando a ideia de forte consenso interno em torno dos objetivos e das metas a atingir, tornou-se, em poucos anos, uma opção estratégica assumida num crescente número de escolas. Adotou, por essa via, modelos teóricos de referência, estilos de liderança, formas de prestação de contas, modelos de trabalho pedagógico e práticas de gestão inspirados no mundo dos negócios e da gestão empresarial.

Num clima ideológico marcado pelo discurso da excelência e perante a retórica hoje dominante do mérito e da competitividade como instrumentos de gestâo promotores do crescimento, do sucesso e da responsabilidade, revela-se difícil corresponder ao apelo de Riccardo Petrella (2002, p. 117): "É preciso deslegitimar o princípio da competitividade e afirmar que a prioridade não é a competitividade mas sim a solidariedade". Em qualquer dos casos, a introdução da competitividade como princípio de organização e gestão, de produção de resultados de excelência, de uma pedagogia empreendedora, de uma avaliação estandardizada, de fabricaçáo da distinçáo institucional, nunca se abate apenas sobre as unidades escolares nem sobre os sistemas de ensino que são objeto de comparação e de hierarquização. Incide, forçosamente, sobre os alunos, os professores e as famílias, sobre as concepções de educação e de cultura escolar, sobre a gestão do currículo, as práticas pedagógicas, os sistemas de regras dentro e fora da sala de aula, as modalidades de avaliaçáo pedagógica, as relaçóes de poder, os processos de socializaçáo e de convivialidade. E a competitividade degenerada, sobretudo entre desiguais, cedo tende para a lei do mais forte, para a alienaçáo dos sujeitos, para a perpetuação e legitimação das desigualdades, para as práticas de segregação interescolar e intraescolar dos alunos, para a rivalidade entre professores, podendo transformar-se numa pedagogia contra o outro.

Essa meritocracia contemporânea, em contraste com o caráter distópico e a conotação pejorativa que lhe fora atribuída por Michael Young no seu livro de 1958, em que critica concepçóes individualistas, essencialistas e eugenistas, bem como a "igualdade de oportunidades para ser desigual" (YOUNG, 1958, 
p. 103), assumiria agora a condição de um ideal positivo, destacando a ambição pessoal como crucial, a inteligência como nuclear, a aplicação do esforço pessoal como questáo meramente volitiva, a competiçáo como algo natural e que deve ser encorajado logo na escola, bem como a natureza puramente individual dessa competição (ALLEN, 2012, p. 371-377).

\section{O lideracionismo e a erosão da gestão democrática das escolas}

De acordo com a lógica empresarial e à semelhança das escolas privadas, o controle democrático diretamente estabelecido sobre as escolas públicas deveria desaparecer, assim desburocratizando, pretensamente, as escolas, tornando-as mais eficazes e responsáveis perante as escolhas da comunidade e das famílias. Uma visáo clara, objetivos estabelecidos rigorosamente e com ambição, lideranças educacionais mais fortes, professores mais profissionais, famílias com capacidade de exercer a escolha da escola estariam na base de escolas mais eficazes e com melhores resultados. Descentralização, competição e escolha seriam os segredos da escola eficaz, incompatíveis com lógicas de gestão e de controle democráticos; mercados, não democracias, seriam os referenciais mais compatíveis com escolas em busca da excelência.

De modo semelhante, a atividade de gestáo aparece genericamente associada a líderes unipessoais com poderes reforçados em termos de autonomia de gestão, de controle e de escrutínio sobre a ação de docentes e discentes, embora frequentemente em situação de ampla subordinação perante as autoridades políticas nacionais ou locais. A colegialidade democrática surge, nesse contexto, como um valor denegado ou de importância diminuída, dado que assim se torna mais fácil atomizar cada diretora e isolar cada professor, do que resulta que o trabalho cooperativo e a solidariedade entre uns e outros é mais difícil de alcançar, antes favorecendo a hierarquização e a competição. Pelo contrário, o crescente elogio da liderança unipessoal das escolas, que, como nas empresas, seria responsável pela apresentação de uma visão, de um projeto e de uma equipe, revela a desvalorização dos processos eleitorais e da natureza colegiada dos órgáos de direção e gestão. Mas revela, sobretudo, como a maioria dos atuais discursos políticos em torno da descentralização e da autonomia se inscreve fora de uma concepção democrática de governo das escolas, afastando a participação dos atores socioeducativos dos processos políticos de tomada das decisôes.

O diretor escolar poderá, portanto, ser um executivo subordinado perante as autoridades políticas, embora, por outro lado, mais poderoso diante da generalidade dos atores escolares, agora vistos como seus subordinados. Curiosamente, o livro de Chubb \& Moe (1990, p. 56) - Politicas, Mercados e as Escolas da América —, obra seminal do gerencialismo educacional, admite esse possível papel do diretor escolar, afirmando os seus autores: "Talvez seja melhor pensar no diretor de escola pública como um gestor do nível mais baixo enquanto líder. 
No sector público, o diretor é um burocrata com responsabilidade de supervisão perante uma agenda pública". Observam os mesmos autores que "a maior parte das decisóes importantes acerca da política foi tomada já pelas autoridades; elas definem os objetivos e espera-se que o diretor os administre" (CHUBB; MOE, 1990, p. 56). E concluem, por isso, logo a seguir (CHUBB; MOE, 1990, p. 56): "Os verdadeiros líderes da escola pública são as autoridades, não o diretor".

$\mathrm{O}$ diretor tende a ser um gestor do dia a dia, um gerente geral que executa a estratégia superior, implementa, informa a hierarquia, mesmo detendo alguma discricionariedade técnica e aumentando a capacidade de supervisão do pessoal que se encontra sob sua gestão direta. Trata-se de alguém que é responsável por executar localmente as medidas de política educativa e, por isso, de alguém a quem, individualmente, se pode passar a assacar responsabilidades; uma garantia de que será muito mais exigente para com os seus subordinados, passando, igualmente, a assacar-lhes as responsabilidades que lhes caibam.

Assiste-se a uma generalizada erosão da democratizaçáo do governo das escolas, a uma desafeição perante a colegialidade dos seus órgãos de direção e diante da participaçáo dos atores nos processos de decisáo político-educacional. Tal não é, porém, totalmente incompatível com um módico de democracia restrita a elites, atores iniciados, representantes de empresários e de outros setores interessados. Setores sociais que são capazes de exigir das escolas a satisfação das principais necessidades de formação das qualificaçôes e das competências consideradas essenciais à promoção do empreendedorismo e da empregabilidade, da competitividade econômica e da produtividade, da flexibilidade laboral e da adaptação funcional ao mercado de trabalho (LIMA, 2014).

Cenário em que a escola, como dizia um professor português entrevistado num estudo (FERREIRA, 2010, p. 191), se pode transformar "numa ditadura com uma cara de democracia. Porque tudo se centra na figura do diretor". $\mathrm{Ou}$ seja, é uma situação em que a democracia na gestão democrática das escolas é já de intensidade baixa, operacional, talvez uma "pós-democracia", como defende criticamente e em termos mais gerais Colin Crouch (2004), em busca do nível máximo de participação mínima; ou mesmo que começa a ser profundamente afetada por princípios que recusam os pressupostos da democracia liberal para, como se tem visto em variados contextos, impor uma democracia iliberal e, portanto, várias práticas não substantivamente democráticas.

\section{Riscos de desumanização: a pedagogia contra o outro e o stakhanovismo educacional}

O adensamento da cultura empresarial e de negócios no mundo da educação, aqui objeto de breves referências quanto a um limitado número de dimen- 
sóes já com expressão suficientemente visível, revela quanto a competitividade exacerbada tem embebido o universo da pedagogia, a cultura escolar e as práticas organizacionais. Trata-se de um elemento central a uma espécie de revolução empreendedorista, em busca de novos padróes de governança escolar. Para além disso, a acentuação do caráter instrumental e adaptativo da educação atingiu proporçóes difíceis de imaginar quando, no início do século XX, John Dewey (2007) criticava a "educação-instrumento", de tipo restrito, vocacional e utilitário, tendo a propósito afirmado: "Existe o perigo de que a educação vocacional seja interpretada, tanto em teoria como na práctica, como uma educação profissional: como um meio de assegurar a eficiência técnica em futuras actividades especializadas" (DEWEY, 2007, p. 267-268). Como concluiu o autor, "a educação tornar-se-ia, desta forma, um instrumento para perpetuar, imutável, a existente ordem industrial da sociedade, em vez de actuar como meio para a sua transformação" (DEWEY, 2007, p. 267-268).

A solidariedade tende agora a ser substituída pela rivalidade, e o lema pedagógico que emerge é "competir para progredir" (PORTER, 1993). Os riscos de reelitização da educação, de seleção e de discriminação, de alienação, em suma, de desumanização da educação, tornam-se consideravelmente mais elevados. Theodor Adorno (2000, p. 161-162) tinha já chamado a atenção para o fato de a competitividade ser, no fundo, contrária a um projeto humanista de educação, pelo menos quando a educação é entendida, como na perspectiva freiriana, como um processo de humanização dos seres humanos (FREIRE, 1997). Por isso, Stéphane Hessel e Edgar Morin (2011) defenderam a necessidade de uma "descompetitivizaçâo da sociedade" e de uma educação não "sobreadaptada" aos imperativos da economia, mas, pelo contrário, mais solidária e cooperativa.

Num mundo social em compita permanente e generalizada, sob uma impiedosa rivalidade econômica que se traduz por guerras comerciais e outras, não existiria alternativa à aquisição das melhores competências para competir e para ganhar. A formação seria agora o núcleo estratégico de uma nova "arte da guerra" e a aprendizagem competitiva a sua arma mais eficaz, no contexto mais geral de uma pedagogia contra o outro, que, ao fabricar os vencedores, produziria necessariamente os vencidos e, mais do que isso, legitimaria a sua existência, pois nesse quadro de rivalidade os vencidos são indispensáveis, em condição e em número significativo, para fazer sobressair os vencedores. É sobre estes que agora se edifica uma imagem institucional de excelência educativa e de altos padróes de qualidade escolar. É o que faz o governo pelo mérito, homogeneizando os alunos por intermédio de um processo de alunização de crianças e de jovens que se manifesta indiferente às diferenças, assim inscrevendo-os na grande competição, como se todos partissem da mesma posição e com recursos idênticos.

A competitividade exacerbada, enquanto princípio ético-político, moral e gerencial, tende a degenerar no individualismo, na instrumentaliza- 
ção própria da racionalidade meramente formal, na alienação. Pelo contrário, como observou István Mészáros (1975, p. 289-290), "transcender positivamente a alienação constitui, em última análise, uma tarefa educativa", tarefa que, por isso, não coincide apenas com "interiorização", "adaptação" e "estabilização" visando à produção de "habilidades" economicamente valorizáveis e à formação de quadros, por meio de métodos orientados para o controle político e o produtivismo.

Contudo, tal como há muito descortinamos elementos neotaylorianos na organização e na gestão da educação (LIMA, 1994), em busca incessante do meio ótimo, da eficiência e da maior produtividade, mediante a padronização de regras e processos, de formas de controle automático, de sistemas de incentivo e da açáo dos departamentos que pensam, também parece possível articular esse taylorismo social com uma cultura integradora baseada numa performatividade mais ou menos estetizada, fortemente socializadora, quando não doutrinadora, capaz de produzir, de publicitar e de celebrar os seus heróis. Ou seja, gestores, professores, alunos, famílias engajados na produção dos melhores resultados, sob ambiente meritocrático, altamente competitivo e contábil, sempre dispostos a ultrapassar as suas metas e as metas de outros que os venham a suplantar, emulando as práticas consideradas exemplares e procurando atingir patamares cada vez mais inacessíveis de distinção social. As agora chamadas "melhores práticas", frequentemente descontextualizadas e naturalizadas, impostas segundo referenciais racional-formais e respectivos "fatos" sob medição, constituem o âmago dos processos de benchmarking em nível político-institucional (ver, entre outros, BRUNO; DIDIER, 2013; BRUNO, 2014), servindo simultaneamente como exemplum a emular e adotando como processo intrínseco e metodologia a seguir a própria competição, também simultaneamente considerada como meio e fim que não conheceria alternativa racional.

Daqui pode resultar uma espécie de stakhanovismo educacional, talvez compatível com a "revoluçáo permanente" anunciada pelas teorias gerencialistas. Não se trata dos recordes de produtividade, aliás devidamente remunerados, de Alexey Stakhanov nas minas de carvão de Donetz, na União Soviética de meados de 1930, nem de um taylorismo socialista que produziu os seus heróis da revolução sob a direção política de Stalin e de Molotov (ver, por exemplo, DAVIES; KHLEVNYUK, 2002). Mas tratou-se de uma visão do mundo, de um front cultural (MIGUEL, 2007), de certo dirigismo e vanguardismo modernizador que nos permite estabelecer algumas semelhanças com a emergente pedagogia empreendedorista e competitiva que agora, congruente com o novo capitalismo, apresenta múltiplos riscos de instrumentalização e desumanização da educação. Embora apelando à adesão voluntária e engajada a novos processos de intensificação do trabalho discente e docente, as políticas educacionais e as organizaçóes escolares tendem a exercer processos de liderança fortes, a criar instrumentos de controle e de disciplinação, a usar processos sofisticados de 
condicionamento por meio de uma organização hipermecanicista que, assente no mundo digital e em processos de vigilância individualizada, se apresenta, paradoxalmente, sob o discurso da descentralização e da autonomia, da flexibilidade, da participação dos interessados e da pós-burocracia. Vai, entretanto, estetizando as suas experiências e contruindo os seus rituais culturais integradores e os seus processos simbólicos de celebração e socialização (prêmios, quadros de excelência, atribuição de títulos, realização de cerimônias públicas etc.). Mas a irracionalidade pedagógica (substantiva), inerente aos excessos desse tipo de racionalidade econômica e técnico-instrumental (formal), tal como em termos de produção industrial e de serviços sucedeu historicamente com o movimento stakhanovista na União Soviética de meados da década de 1930, fica cada vez mais clara à medida que os eventuais efeitos de curto prazo se esgotam ou estabilizam em termos de resultados. E que as crianças e os jovens escolares apresentam certas resistências culturais e sociomorais, mesmo no caso dos chamados alunos de mérito, os professores acusam desgaste, esmorecem ou mesmo adoecem, que há notícias de famílias que procuram escolas especificamente não competitivas, que o ensino doméstico aumenta em vários países, que certos movimentos pedagógicos continuam a insistir nas vantagens do trabalho cooperativo.

As práticas pedagógicas que implicam certa competição entre alunos são muito antigas, envolvendo vitórias e derrotas sob muita disciplina, castigos e privaçóes, havendo registro delas, por exemplo, nos colégios dos padres-mestres jesuítas desde o século XVI (FREYRE, 1936, p. 94-98). A competição surge também associada a dimensóes de motivação e superação, por vezes ao espírito de equipe e ao chamado fair play desportivo, tão típico, em certos períodos históricos, na educação liberal e na formação dos gentlemen. É, ainda, associada a uma dimensão lúdica e de fruição com potencial pedagógico reconhecido por muitos. A verdade é que, na presente escala, intensidade e propósito econômico-empreendedor, ela se apresenta, pelo menos em regimes políticos democráticos, com uma centralidade axiológica e organizacional dificilmente superável na história da educação escolar pública. Sobretudo porque essa pedagogia empreendedorista, potencialmente contra o outro, é muito mais do que um sistema pedagógico alicerçado em opções didáticas e em rigorosas formas de avaliação externa, padronizada e universal. É, antes de tudo, uma nova concepção utilitarista de educação e aprendizagem, um princípio reformador das escolas e dos professores, dos alunos, da vida nas escolas e da sua organização e gestão, procurando forte articulação subordinada e funcional relativamente à competitividade econômica, ao empreendedorismo e a uma cultura de rivalidade que se espera seja emulada e ampliada, produzindo personalidades assertivas e resilientes, seres humanos ajustáveis, dotados de grande mobilidade e capacidade de prontidão. Os correspondentes riscos de desumanização dessa educação e formação serão, eventualmente, considerados meros efeitos colaterais, riscos inerentes a todo o processo de reforma e modernização. 


\section{Referências}

ADORNO, T. W. Educação e emancipação. Rio de Janeiro: Paz e Terra, 2000.

ALLEN, A. Life without the ' $\mathrm{X}$ ' Factor: meritocracy past and present. Power and Education, v. 4, n. 1, p. 4-19, 2012. https://doi.org/10.2304\%2Fpower.2012.4.1.4

BALL, S. J.; YOUDELL, D. Hidden privatisation in public education. Bruxelas: Education International, 2008.

BRUNO, I. Des faits, des faits, des faits! À propos du gouvernement par les chiffres et autres donnés probantes (dans l'éducation e ailleurs). Revista Lusófona de Educaçáo, Lisboa, n. 28, p. 25-42, 2014.

BRUNO, I.; DIDIER, E. Benchmarking: L'État sous pression statistique. Paris: Éditions La Découverte, 2013.

CHUBB, J. E.; MOE, T. M. Politics, markets and America's schools. Washington, D.C.: The Brookings Institution, 1990.

CLARKE, J.; NEWMAN, J. The managerial state: Power, politics and ideology in the remaking of social welfare. Londres: Sage, 1997.

CROUCH, C. Post-Democracy. Cambridge: Polity Press, 2004.

CROZIER, M. The bureaucratic phenomenon. Chicago: The University of Chicago Press, 1964.

DAVIES, R. W.; KHLEVNYUK, O. Stakhanovism and the Soviet economy. Europe-Asia Studies, v. 54, n. 6, p. 867-903, 2002. https://doi.org/10.1080/0966813022000008447

DEWEY, J. Democracia e educação. Lisboa: Didáctica Editora, 2007.

FAYOL, H. Administração industrial e geral. São Paulo: Atlas, 1984.

FERREIRA, N. O director, o novo rosto da escola? Um estudo de caso sobre concepçóes e práticas do director na gestáo de uma escola secundária. Dissertação (Mestrado) Instituto de Educação da Universidade do Minho, Braga, 2010.

FORD, H. Henry Ford por ele mesmo. São Paulo: Martin Claret, 1995.

FREIRE, P. Política e educaçáo. São Paulo: Cortez, 1997.

FREYRE, G. Sobrados e mucambos: Decadencia do patriarchado rural no Brasil. São Paulo: Companhia Editora Nacional, 1936.

GALBRAITH, J. K. The new industrial state. Harmondsworth: Penguin Books, 1974.

GELPI, E. Formación de personas adultas: inclusión y exclusión. Xàtiva: Edicions del CREC, 2009.

GORE, A. (org.). Da burocracia à eficácia: reinventar a administração pública. Lisboa: Quetzal, 1996.

GOULDNER, A. Patterns of industrial bureaucracy. Glenco: Free Press, 1954. 
HADJI, C. A avaliação, regras do jogo. Porto: Porto Editora, 1994.

HESSEL, S.; MORIN, E. Le chemin de l'espérance. Paris: Fayard, 2011.

LAWN, M. Voyages of measurement in education in the twentieth century: experts, tools and centres. European Educational Research Journal, v. 12, n. 1, p. 108-111, 2013. Disponível em: <http://eer.sagepub.com/content/12/1/108.full.pdf + html>. Acesso em: 3 jan. 2019. http://dx.doi.org/10.2304/eerj.2013.12.1.108

LIMA, L. C. A gestão democrática das escolas: do autogoverno à ascensão de uma pósdemocracia gestionária? Educaçáo e Sociedade, Campinas, v. 35, n. 129, p. 1067-1083, 2014. http://dx.doi.org/10.1590/ES0101-73302014142170

LIMA, L. C. Educação de adultos e construção da cidadania democrática: para uma crítica do gerencialismo e da educação contábil. Inovaçáo, Lisboa, v. 9, n. 3, p. 283-297, 1996.

LIMA, L. C. Elementos de hiperburocratização da administração educacional. In: LUCENA, C.; SILVA JÚNIOR, J. R. (orgs.). Trabalho e educaçáo no século XXI: experiências internacionais. São Paulo: Xamã, 2012a. p. 129-158.

LIMA, L. C. Evaluación hiperburocrática. Profesorado, Revista de Currículum e Formación del Profesorado, Granada, v. 20, n. 3, p. 87-118, 2016.

LIMA, L. C. Modernização, racionalização e optimização. Perspectivas neo-taylorianas na organização e administração da Educação. Cadernos de Ciências Sociais, Porto, n. 14, p. 119-139, 1994.

LIMA, L. C. O paradigma da educação contábil: políticas educativas e perspectivas gerencialistas no ensino superior em Portugal. Revista Brasileira de Educaçáo, São Paulo, n. 4, p. 43-59, 1997.

LIMA, L. C. Patterns of institutional management: Democratisation, autonomy and the managerialist canon. In: NEAVE, G.; AMARAL, A. (orgs.). Higher education in Portugal, 1974-2009. A nation, a generation. Dordrecht: Springer, 2012b. p. 287-306.

LIMA, L. C. Privatização lato sensu e impregnação empresarial na gestão da educação pública. Currículo sem Fronteiras, v. 18, n. 1, p. 129-144, 2018.

MEIRA, M. A burocracia electrónica: um estudo sobre as plataformas electrónicas na administraçáo escolar. Tese (Doutoramento) - Instituto de Educação da Universidade do Minho, Braga, 2017.

MÉSZÁROS, I. Marx's theory of alienation. Londres: Merlin Press, 1975.

MIGUEL, J. D. O taylorismo soviético como front cultural. Projeto História, São Paulo, v. 34, p. 109-131, 2007.

OSBORNE, D.; GAEBLER, T. Reinventing government: How the entrepreneurial spirit is transforming the public sector. Nova York: Plume, 1992.

PEREIRA, C. Ciberadmininistraçáo educacional e identidade docente: dinâmicas de poder e lógicas de sobrevivência. Dissertação (Mestrado) - Instituto de Educação da Universidade do Minho, Braga, 2009. Disponível em: <http://repositorium.sdum. uminho.pt/handle/1822/10461>. Acesso em: 7 jan. 2019. 
PETRELLA, R. O bem comum: Elogio da solidariedade. Porto: Campo das Letras, 2002. PORTER, M. E. A vantagem competitiva das naçóes. Rio de Janeiro: Campus, 1993.

RANSON, S. Contesting the school reform in England: Contrasting modes of governance and accountability. Profesorado, Granada, v. 20, n. 3, p. 53-85, 2016.

SALAMON, L. M. The new governance and the tools of public action: An introduction. Fordham Urban Law Journal, v. 28, n. 5, p. 1611-1674, 2000.

SALAMON, L. M. The new governance and the tools of public action: An introduction. In: SALAMON, L. M. (org.). The tools of government: A guide to the new governance. Oxford: Oxford University Press, 2002. p. 1-47.

SAURA, G.; MUÑOZ, J. L. Prácticas neoliberales de endo-privatización y nuevas formas de resistencia colectiva en el contexto de la política educativa española. Revista Educación, Política y Sociedad, v. 1, n. 2, p. 43-72, 2016.

SMYTH, J. (org.). A socially critical view of the self-managing school. Londres: The Falmer Press, 1993.

SMYTH, J. The disaster of the "self-managing school" - genesis, trajectory, undisclosed agenda, and effects. Journal of Educational Administration and History, v. 43, n. 2, p. 95-117, 2011. https://doi.org/10.1080/00220620.2011.560253

SOROKIN, P. A. Fads and foibles in modern sociology. Chicago: Gateway Edition, 1965.

TAYLOR, F. W. Princípios da administração científica. São Paulo: Atlas, 1982.

UNIÃO EUROPEIA. Comissão Europeia. Comunicação da Comissão ao Parlamento Europeu, ao Conselho, ao Comitê Econômico e Social Europeu e ao Comitê das Regiōes. Uma nova agenda de competências para a Europa: trabalhar em conjunto para reforçar o capital humano, a empregabilidade e a competitividade. Bruxelas: Comissão Europeia, 2016. Disponível em: <https://www.dges.gov.pt/pt/content/nova-agenda-decompetencias-para-europa $>$. Acesso em: 2 nov. 2016.

UNIÂO EUROPEIA. Commission of the European Communities. Adult learning: It is never too late to learn. Bruxelas: Commission of the European Communities, 2006a. Disponível em: <https:/www.cedefop.europa.eu/en/news-and-press/news/adult-learningit-never-too-late-learn>. Acesso em: 12 nov. 2010.

UNIÂO EUROPEIA. Commission of the European Communities. Communication from the Commission. Making a European area of lifelong learning a reality. Bruxelas: Commission of the European Communities, 2001. Disponível em: <http://viaa.gov.lv/ files/free/48/748/pol 10 com en.pdf $>$. Acesso em: 12 nov. 2010.

UNIÃO EUROPEIA. Council of the European Union. Council conclusions of 12 May 2009 on a strategic framework for European cooperation in education and training ('ET 2020'). Bruxelas: Council of the European Union, 2009. Disponível em: <https://www.cedefop.europa.eu/files/education benchmarks 2020.pdf>. Acesso em: 15 nov. 2010. 
UNIÃO EUROPEIA. European Parliament and Council of the European Union. Decision No. 1720/2006/EC of the European Parliament and of the Council of 15 November 2006 establishing an action programme in the field of lifelong learning. Bruxelas: European Parliament and Council of the European Union, 2006b. Disponível em: $<\underline{\text { https: } / /}$ eur-lex.europa.eu/LexUriServ/LexUriServ.do?uri=OJ:L:2006:327:0045:0068:en:PDF>. Acesso em: 15 nov. 2010.

UNIÃO EUROPEIA. European Parliament and Council of the European Union. Recommendation of the European Parliament and of the Council of 18 December 2006 on Key competences for lifelong learning. Bruxelas: European Parliament and Council of the European Union, 2006c. Disponível em: <https://eur-lex.europa.eu/ LexUriServ/LexUriServ.do?uri=OJ:L:2006:394:0010:0018:en:PDF>. Acesso em: 15 nov. 2010.

VERGER, A.; NORMAND, R. Nueva gestión pública y educación: elementos teóricos y conceptuales para el estudio de un modelo de reforma educativa global. Educaçáo \& Sociedade, Campinas, v. 36, n. 132, p. 599-622, 2015.

WEBER, M. Economía y sociedad: esbozo de sociología comprensiva. México: Fondo de Cultura Económica, 1984.

YOUNG, M. The rise of the meritocracy, 1870-2033. An essay on education and equality. Londres: Thames and Hudson, 1958.

\section{SOBRE O AUTOR}

Licínio C. Lima é Professor Catedrático do Departamento de Ciências Sociais da Educação - Instituto de Educação da Universidade do Minho

Recebido em 23 de janeiro de 2019.

Aceito em 18 de abril de 2019. 